\title{
Ambient Air Pollution Status of Addis Ababa City; The Case of Selected Roadside
}

\author{
Dejene Tsegaye ${ }^{*}$, Seyoum Leta, Mohammed Mazharuddin Khan \\ Center for Environmental Science, College of Natural and Computational Science; Addis Ababa University, Addis Ababa, Ethiopia \\ Email address: \\ dejene.tsegaye@aau.edu.et (D. Tsegaye), seyoum.leta@aau.edu.et (S. Leta),dr_mazhar_khan@yahoo.co.in (M. M. Khan) \\ ${ }^{*}$ Corresponding author
}

\section{To cite this article:}

Dejene Tsegaye, Seyoum Leta, Mohammed Mazharuddin Khan. Ambient Air Pollution Status of Addis Ababa City; The Case of Selected Roadside. American Journal of Environmental Protection. Vol. 8, No. 2, 2019, pp. 39-47. doi: 10.11648/j.ajep.20190802.11

Received: February 14, 2019; Accepted: April 3, 2019; Published: June 29, 2019

\begin{abstract}
The Objective of the present study was to determine the concentration level, spatial and temporal variation of air pollutants (Carbon monoxide, Volatile organic carbon, Nitrogen dioxide, and Sulfur dioxide) from vehicular emission in ambient air of Addis Ababa city. Measurements were taken at sixty five roadsides sites for all the above selected pollutants. The overall (mean $\pm \mathrm{SD}$ ) of Addis Ababa city roadsides Carbon monoxide, Volatile organic carbon, Nitrogen dioxide, and Sulfur dioxide concentration level were $4.82 \pm 3.60 \mathrm{ppm}, 317.52 \pm 221.52 \mu \mathrm{g} / \mathrm{m}^{3}, 0.12 \pm 0.16 \mathrm{ppm}$ and $0.23 \pm 0.20 \mathrm{ppm}$ respectively. Spatial variation were observed for all the pollutants; the highest Carbon Oxide, Volatile organic carbon, Nitrogen dioxide, and Sulfur dioxide concentration were recorded at SS16, SS34, SS39 and SS6 sites whereas the lowest at SS6, SS36, SS6 and SS19 respectively. At most of the sites high Carbon Oxide and volatile organic carbon concentrations were also observed at early in the morning and late afternoon. The temporal variation of Nitrogen dioxide and Sulfur dioxide were not significant at all sites under the study at $p<0.05$. The morning and the late afternoon peaks indicate that those pollutants were emitted where vehicular traffic was high. The roadside concentrations of all the pollutants under the study were high and needs continuous monitoring and exploring of mitigation techniques.
\end{abstract}

Keywords: Ambient Air Pollution, Roadsides, Air Pollutants, Addis Ababa, Volatile Organic Carbon

\section{Introduction}

Air pollution generated from vehicles has become a major cause of worldwide scientific and public concern. The estimate of the air pollution to global mortality based on World Health Organization (WHO) indicates even million deaths worldwide in the year 2012. However, 3.7 and 4.3 million are only due to Ambient Air Pollution (AAP) and Indoor Air Pollution (IAP) respectively [1, 2]. Population growth, limited emission control technology, substantial scale of urbanization, increased demand of transportation service, land use without planning, low quality fuels, age of vehicles, increased road congestion and lack of effective transport are among the factors contributing to enhanced vehicular urban air pollution [2-6]. The combined effects of urban air pollution factors create adverse air pollution by forming traffic air pollution. If it is not controlled or monitored effectively and timely, the deterioration will increase continually in cities of developing countries $[6,7]$.
Therefore, air pollution is one of the leading global public health threats. The following health problems like cardiovascular disease (stroke and ischemic heart disease), respiratory disease (asthma, lung cancer, acute respiratory infections in children and chronic obstructive pulmonary disease) are mainly linked with traffic air pollution exposure. The impact of air pollution is severe for sensitive population subgroups (children and elders), pedestrians who walk along busy roads, traffic police and street retailer who spend their time on and along congested roads, work or occupations like taxi and truck drivers $[1,8,9]$.

Urban environment of both developed and developing countries like Ethiopia, vehicular emission pollution are a major source of emissions of ultrafine particles in ambient/outdoor air both at national and local level [3, 4, 5, $9,10]$. Ninety $(90 \%)$ urban air pollution is rapidly growing and expanding in cities like Addis Ababa is due to motor vehicle emission.

WHO identified range of pollutants such as particulate 
matter (PM), Carbon Monoxide (CO), Sulfur dioxide $\left(\mathrm{SO}_{2}\right)$, Nitrogen dioxide $\left(\mathrm{NO}_{2}\right)$ and Ozone $\left(\mathrm{O}_{3}\right)$ air pollutants that have a greatest human health importance and The United States (US) National Ambient Air Quality Standard (NAAQS) also include airborne lead $(\mathrm{Pb})$ to the above mentioned air pollutants although more than three thousand substances are known to potentially contaminate urban ambient air [11, 12, 13].

Addis Ababa is among the cities currently undergoing rapid urbanization having considerable investment on buildings, road and transport sectors [14]. The number of vehicles is increasing annually without an expansion of roads in the city which is the main possible factor of the traffic congestion, therefore increasing in traffic pollution level of Addis Ababa. According to NMA, the air quality data of Addis Ababa is not available and data is provided based on the request [15]. Though this subject was extensively studied in cities of developed countries, to the best of our knowledge there are limited research conducted on vehicular pollution level and status in cities of developing countries like Addis Ababa. Therefore, there is a need to set information on the status and level/concentration of vehicular air pollution on roadside of Addis Ababa. Therefore, the present study was undertaken to fill the knowledge gap mentioned above aiming at exploring the concentration level of $\mathrm{CO}$, VOC, $\mathrm{SO}_{2}$, and $\mathrm{NO}_{2}$, their spatial and temporal variation at selected sites of Addis Ababa main roadsides.

\section{Materials and Methods}

\subsection{Study Area Description}

Present study was conducted in Addis Ababa, a capital city of Ethiopia and working center of African Union. Geographically, Addis Ababa has a total land of over 54,000 hectares and of more than four million populations. Addis Ababa, a heart of the country having an altitude ranging between 2,200 - 2,800 meter above sea level with latitude of 9.0300 degree north and longitude 38.7400 degree east. It has 10 sub-cities and 116 woreda's. The sampling sites under the study touch the corridors of the 10 sub-cities corridor.

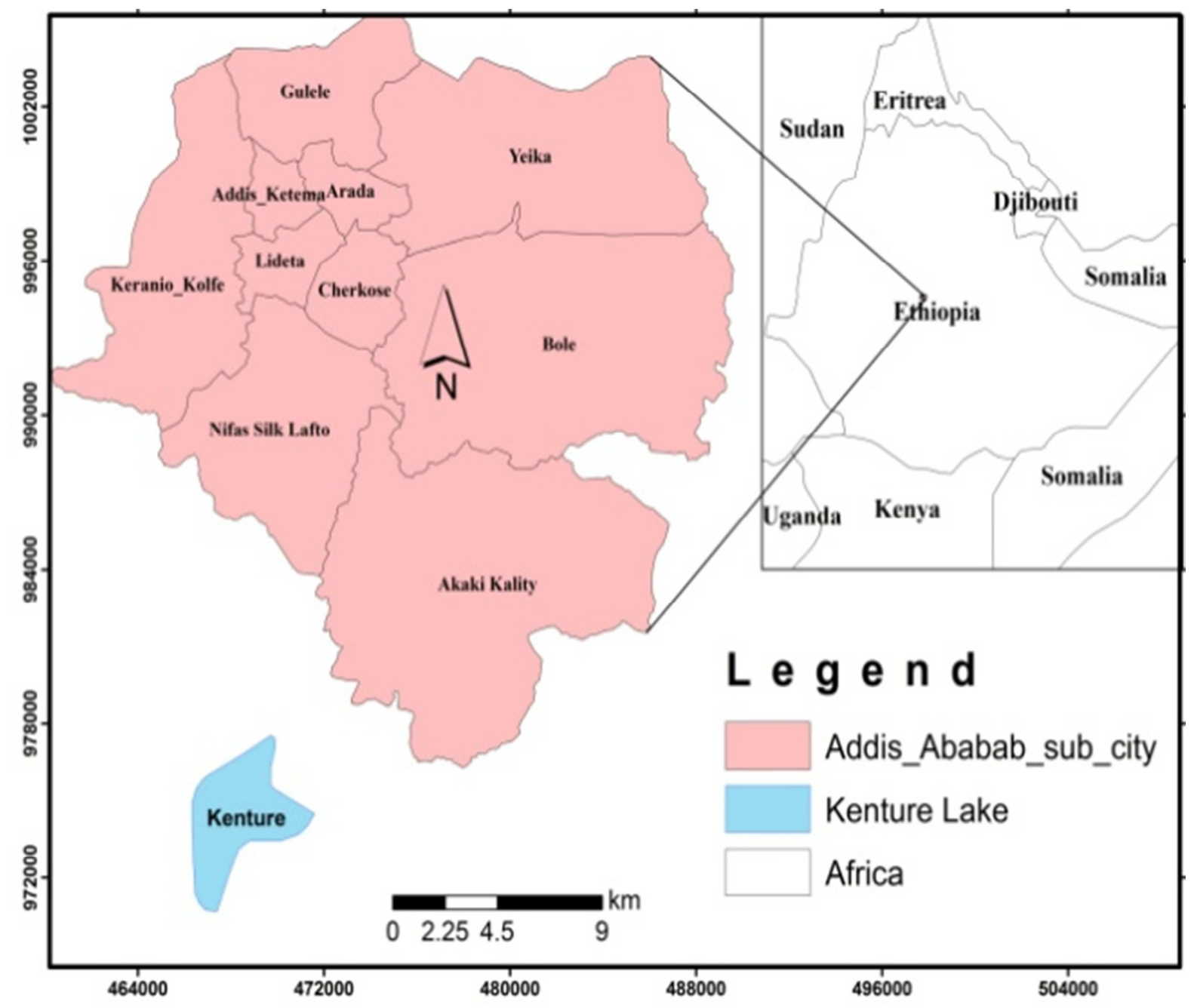




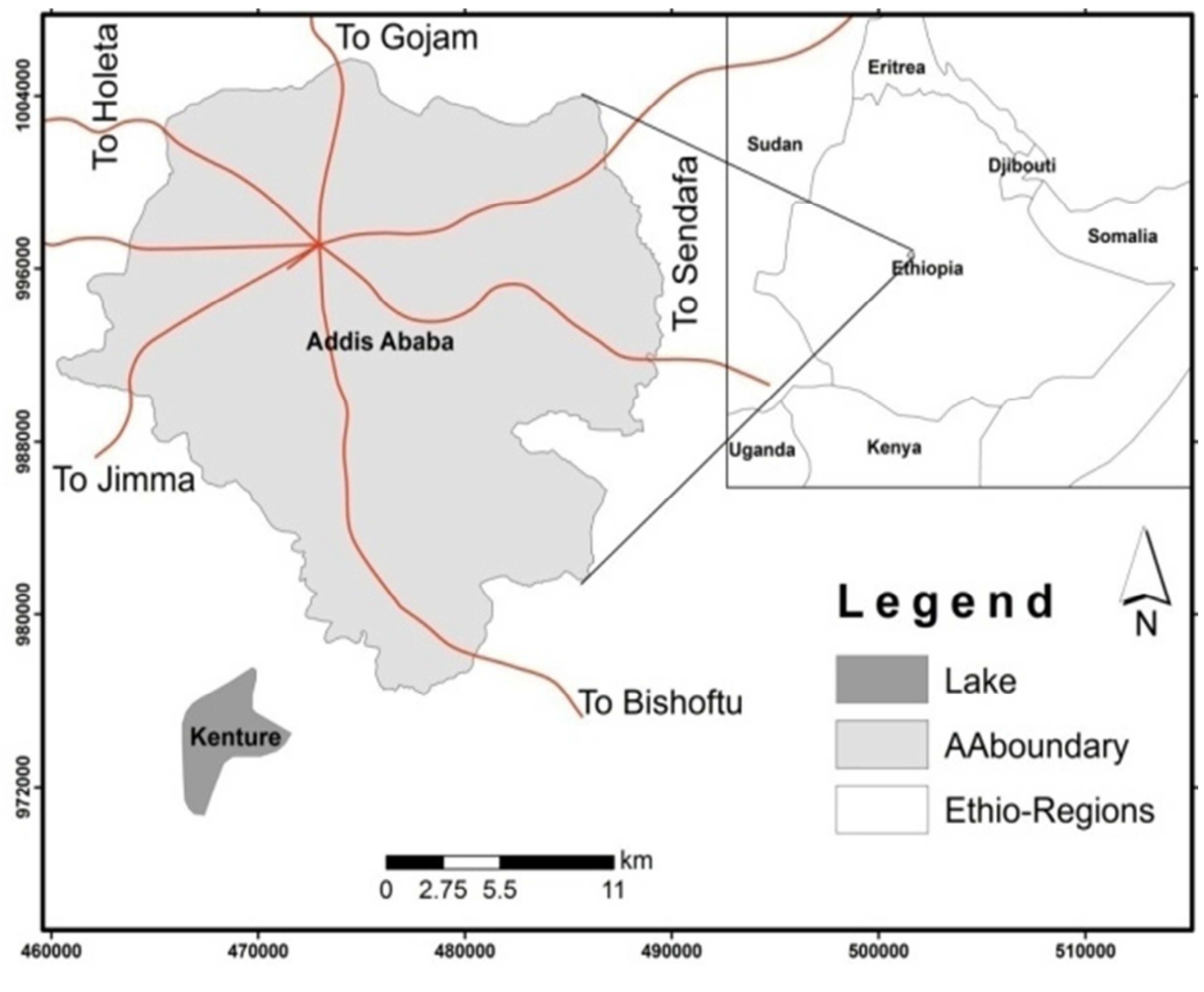

b)

Figure 1. Geographical location of the study Area map a) Sub-cities and b) Main roads of Addis Ababa rooting to different parts of the Country.

\subsection{Study Approach}

Cross-sectional, environmental ambient air sampling approach was followed for the measuring the roadside pollutants gases mainly due vehicles (traffic congestion); $\mathrm{CO}$, VOC, $\mathrm{SO}_{2}$ and $\mathrm{NO}_{2}$ at Addis Ababa city main roadsides from 03 June - 30 August, 2016.

\subsection{Sampling Method}

The sampling sites were selected by a walk through survey on the main roads of the City to assess the vehicle flow from 7:30 - 8:30 am (peak busy hours), 12:00-1:30 pm and 05:30-
06:30 pm (peak busy hours) on working days of the week. Based on the survey sixty five (65) relatively busy roadside sites were selected. Then ambient air measurement was carried out at one hour interval from 7:00 am - 6:00 pm to quantify the concentration of the pollutants $\left(\mathrm{CO}, \mathrm{VOC}, \mathrm{SO}_{2}\right.$, and $\mathrm{NO}_{2}$ ) at each selected sites. Real time measurement of VOC, $\mathrm{SO}_{2}, \mathrm{NO}_{2}$, and $\mathrm{CO}_{2}$ were done using digital aeroqual instrument (portable gas sensor model 500 series, made in USA). GPS (GPS 60 Garmin, made in Taiwan) was used to take the $\mathrm{x}, \mathrm{y}$ and $\mathrm{z}$ coordinates of the sampling/measuring points.

Table 1. Sampling Site Code/ID.

\begin{tabular}{llll}
\hline Sampling Sites & Sampling Site Code/ID & Sampling Sites & Sampling Site Code/ID \\
\hline Arat kilo Commercial bank Selassie branch & SS1 & Kality Meseltegn adebabey \\
Piassa Hermon Hotel & SS2 & Kality KAFDEM & SS34 \\
Megenegna square & SS3 & Legehar, around Medin insurance \\
Saltemiret Mariam Square & SS4 & Ethio-post office main branch \\
Summit Yetebaberut fuel station & SS5 & Taklehaimanot bruk photo \\
Summit Condominium last & SS6 & Merkato big bus Station \\
Arat kilo Minilik School & SS7 & Merkato Near Telle, small (Taxi and Bus Station) \\
Sidist kilo Dibab Café and Restaurant & SS8 & SS40 \\
Shiromeda Condominium & SS9 & Mesalemia (Yekatit 23 Secondary School) \\
Red Terror, Flamingo & SS10 & Kolfe Taxi Station & SS41 \\
Shoa super market & SS11 & Sebategna (Cross Road) \\
Bole millennium taxi station & SS12 & Ayer Tena Taxi Station & SS42 \\
\hline
\end{tabular}




\begin{tabular}{llll}
\hline Sampling Sites & Sampling Site Code/ID & Sampling Sites & Sampling Site Code/ID \\
\hline KazanchisHanan Bakery & SS13 & Kera Mezoria Adebabay (Near Kera org. Station) & SS46 \\
Bole Medehanialem & SS14 & SarbetAdebabay Pushkin (Commercial Bank of & SS47 \\
Bole Brass, Dashin bank & SS15 & Ethiopia) & SS48 \\
Shola Traffic Light & SS16 & Karl Square (Arcobalrnd) & SS49 \\
Kotebe 02 & SS17 & Ethiopia medihanit Fabrica Square & SS50 \\
Karalo & SS18 & German Square (Commercial bank) & SS51 \\
Tafo Square & SS19 & Lemo Cross Road, Taxi Station, NOC & SS52 \\
Stadium Admass College & SS20 & Lemberet Bus Station & SS53 \\
Agona Gotera (Color Furniture) & SS21 & Torhailoch taxi station & SS54 \\
Saris Dawi Building & SS22 & Lideta Mariam & SS55 \\
Ras Desta Hospital & SS23 & Abnet square, tinsaebirahan pharmacy & SS56 \\
Paster Square & SS24 & Autobistera near children cloths & SS57 \\
Asco Square/Winget & SS25 & Addis ketama, Awash bank & SS58 \\
Stadium Infront of Lalibala Hotel & SS26 & Addis ketama school at center & SS59 \\
Hayahulet (Industrial building) & SS27 & Yirga Haile & SS60 \\
Gerjimebrat hail vision school & SS28 & Burayu city Admn. Bereket school & SS61 \\
Semen Hotel, Nafyad Café & SS29 & Burayu Keta (infront of Sifan pharmacy) & SS62 \\
Addisu Gebaya, Commercial Bank & SS30 & Asco Taxi Station & SS63 \\
Tsion Hotel & SS31 & Goro Alemayo Ketema building & SS64 \\
Mexico taxi station & SS32 & Goro square (Riyan car spare part shop) & SS65 \\
Kality Bus station & SS33 & & \\
\hline
\end{tabular}

\subsection{Data Collection and Analysis}

From all sampling sites all the pollutants i.e parameters under the study were collected in one hour interval starting from 7:00 am in the morning to $6: 00 \mathrm{pm}$ in the evening to maximize presence of high vehicular activities on road during the study period. All measurements were made at a range of 0.5-2.0 meter distance from the main road and $1 \mathrm{~m}$ height. The collected data entered to Microsoft excel database for further analysis and interpretation. The graphs were drawn using Origin Pro 8 software. For summarizing all the pollutant concentrations descriptive statistics was used. Mean pollutant concentrations were compared between selected sampling sites by t-tests and a p-value of 0.05 was considered for the statistical significance.

\section{Result and Discussion}

Measurements were taken for parameters under study at sixty five (65) sampling sites during the study period 03 June - 30 August, 2016 which falls in the wet season. The average (mean \pm SD) concentrations of all parameters under study are presented in Table 1. The daily variation patterns of the pollutants $\left(\mathrm{CO}, \mathrm{VOC}, \mathrm{SO}_{2}\right.$ and $\mathrm{NO}_{2}$ ) at (SS42) Merkato; busy business center and country cross Bus Station site of particular day was also indicated in Figure 2.

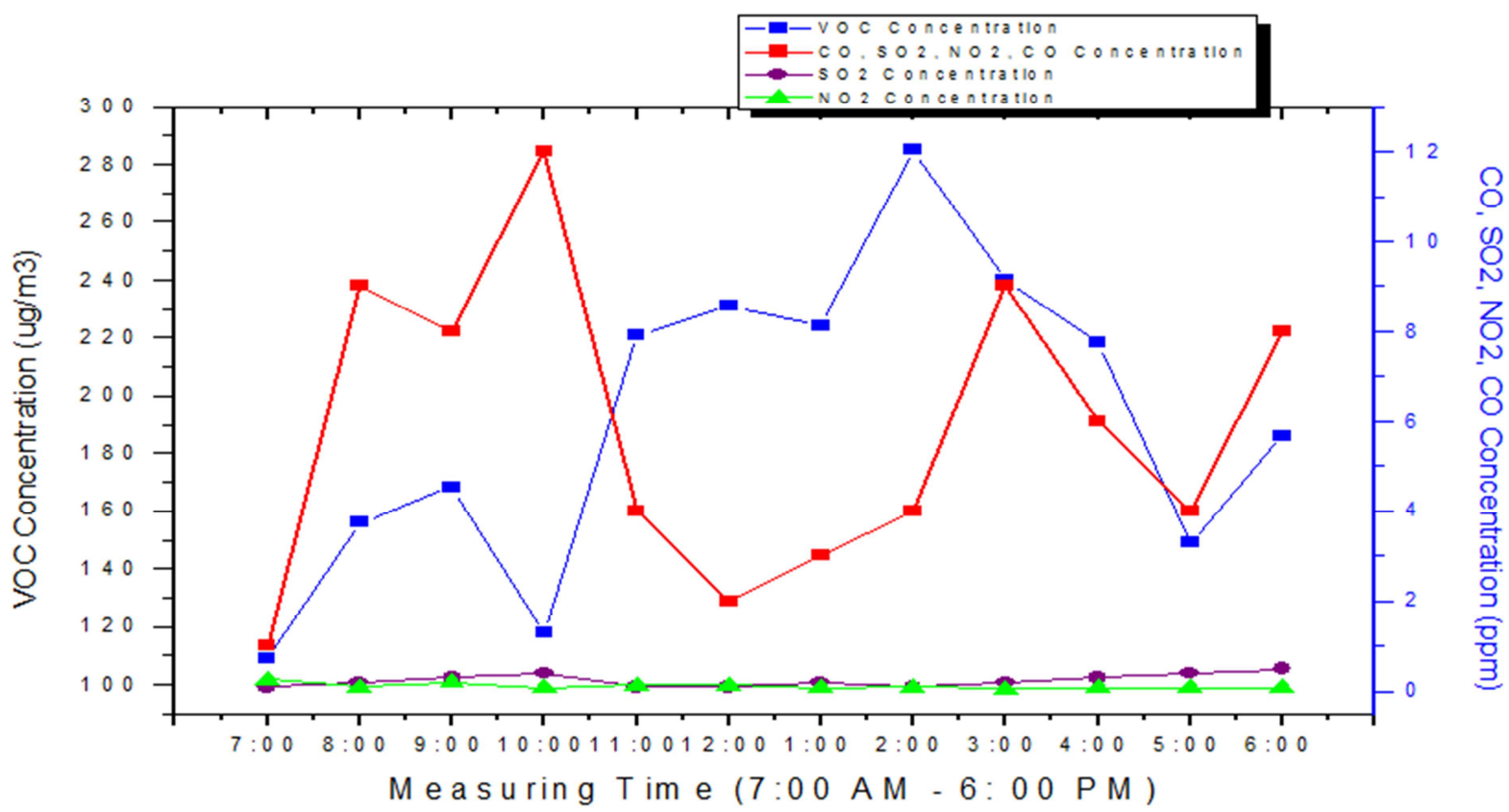

Figure 2. The daily variation patterns of the pollutants (VOC, $\mathrm{SO}_{2}, \mathrm{NO}_{2}$ and CO) at Merkato big Bus Station (SS39) of particular day. 


\subsection{Roadsides CO Concentration}

The arithmetic mean and standard deviation (mean \pm SD) concentrations of $\mathrm{CO}$ at all the sampling site of roadside presented in the Table 2. The overall mean $\pm \mathrm{SD} \mathrm{CO}$ concentration during the sampling period was $4.82 \pm 3.60$ ppm. The overall trends of $\mathrm{CO}$ concentration at all sites during the study period were similar. All the sites (SS16, SS40, SS3, SS41, SS33, SS39, SS38, SS26 and SS35) with high $\mathrm{CO}$ concentration (mean $\pm \mathrm{SD}$ ) are sites located in the high congestion traffic zones of Addis Ababa. The finding of this study is higher than the value reported (2.8 and $2.1 \mathrm{ppm}$ in dry and wet seasons respectively) by [3] which was studied in the same city (Addis Ababa) and lower than the one reported by [16]. The higher concentration of $\mathrm{CO}$ recorded in this research work was may be due to the indirectly increased vehicle congestion in the city. Figure 3 below indicate the trends of $\mathrm{CO}$ concentration at site with highest and lowest roadside $\mathrm{CO}$ concentration.

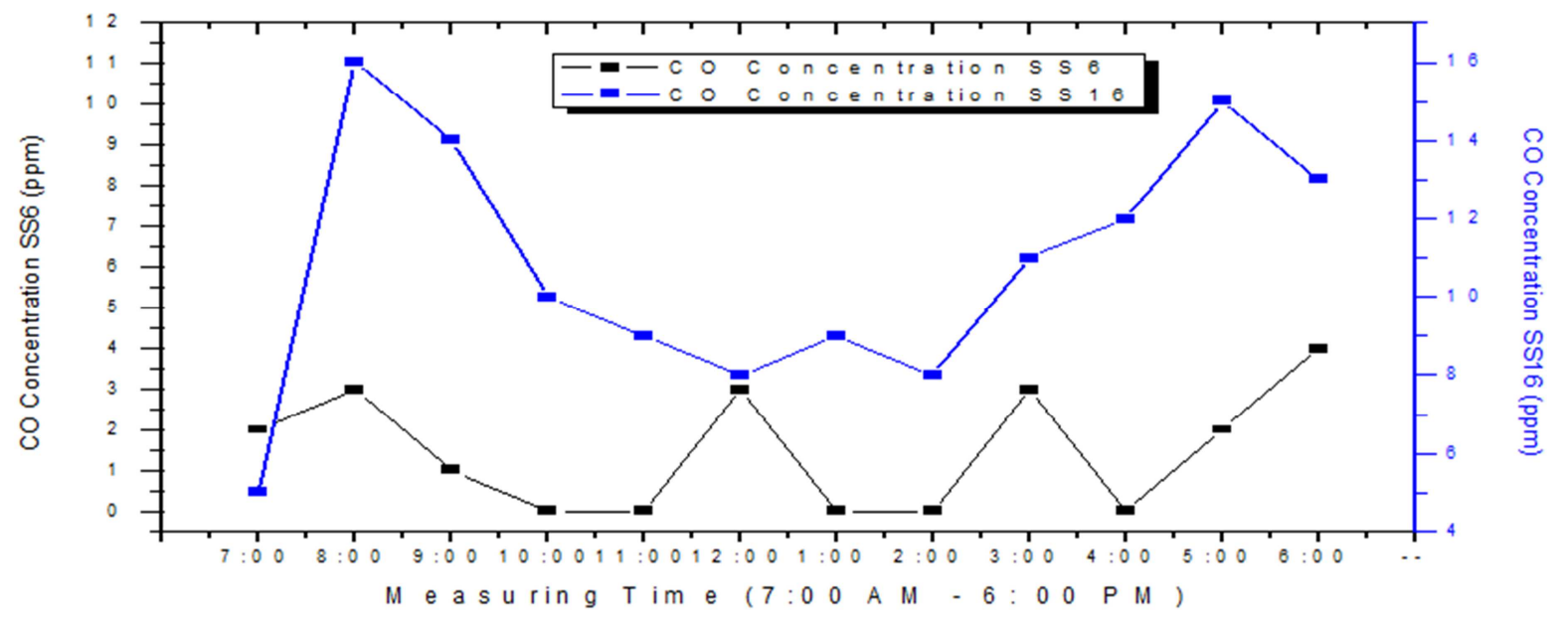

Figure 3. Typical daily CO concentration trends at sites with highest and lowest concentration.

The results obtained from the present study revealed that there is a spatial (site to site) variation $(\mathrm{p}<0.05)$ of $\mathrm{CO}$ concentration even though the overall concentration trend of $\mathrm{CO}$ concentration at all sites was analogous [Figure 2, 3\& 4]. The highest and lowest $\mathrm{CO}$ concentration was recorded at Merkato, which is very busiest business center and country cross bus Station $(10.83 \pm 3.3 .27 \mathrm{ppm})$ and Summit
Condominium square; south-eastern peripheral of Addis Ababa city $(1.20 \pm 1.40 \mathrm{ppm})$ sampling sites respectively. It was indicated in recent study [1] that there is a spatial variation of $\mathrm{CO}$ concentration in Addis Ababa City. Lowest (0.2 ppm) and highest (23.2 ppm) CO concentration in Addis Ababa city at Entoto St. Mary Church and Teklehaimanot square respectively were reported [17].

Table 2. Geographical Location of Sampling site and Average (mean $\pm S D) n=12$ Concentration of all the parameters under study at all study sites.

\begin{tabular}{|c|c|c|c|c|c|c|c|}
\hline $\begin{array}{l}\text { Sampling Site } \\
\text { Code/ID }\end{array}$ & UTM (X) & UTM (Y) & Elevation & $\operatorname{VOC}\left(\mu \mathrm{g} / \mathrm{m}^{3}\right)$ & CO (ppm) & $\mathrm{SO}_{2}(\mathrm{ppm})$ & $\mathrm{NO}_{2}(\mathrm{ppm})$ \\
\hline SS1 & 474186 & 998409 & 2431 & $560.17 \pm 137.08$ & $5.29 \pm 5.50$ & $0.28 \pm 0.09$ & $0.08 \pm 0.04$ \\
\hline SS2 & 472997 & 998487 & 2456 & $598.25 \pm 78.68$ & $7.83 \pm 5.62$ & $0.23 \pm 0.08$ & $0.14 \pm 0.20$ \\
\hline SS3 & 478054 & 997288 & 2391 & $697.33 \pm 293.16$ & $9.92 \pm 5.23$ & $0.29 \pm 0.11$ & $0.08 \pm 0.14$ \\
\hline SS4 & 480720 & 996972 & 2369 & $809.92 \pm 233.36$ & $3.75 \pm 3.89$ & $0.24 \pm 0.10$ & $0.08 \pm 0.01$ \\
\hline SS5 & 483798 & 997276 & 2390 & $574.02 \pm 120.31$ & $3.58 \pm 2.81$ & $0.24 \pm 0.11$ & $0.07 \pm 0.02$ \\
\hline SS6 & 484043 & 992991 & 2320 & $629.91 \pm 72.36$ & $1.20 \pm 1.40$ & $0.21 \pm 0.01$ & $0.05 \pm 0.02$ \\
\hline SS7 & 473941 & 998823 & 2442 & $377.28 \pm 159.88$ & $7.92 \pm 2.97$ & $0.23 \pm 0.11$ & $0.12 \pm 0.14$ \\
\hline SS8 & 473807 & 1000042 & 2505 & $221.15 \pm 43.88$ & $5.58 \pm 4.54$ & $0.18 \pm 0.10$ & $0.06 \pm 0.03$ \\
\hline SS9 & 473819 & 1001585 & 2569 & $207.42 \pm 30.38$ & $3.42 \pm 2.91$ & $0.18 \pm 0.09$ & $0.07 \pm 0.01$ \\
\hline SS10 & 474196 & 995768 & 2355 & $255.73 \pm 145.07$ & $5.08 \pm 2.94$ & $0.24 \pm 0.13$ & $0.11 \pm 0.04$ \\
\hline SS11 & 474949 & 994487 & 2338 & $196.97 \pm 51.97$ & $3.50 \pm 1.98$ & $0.23 \pm 0.13$ & $0.10 \pm 0.03$ \\
\hline $\mathrm{SS} 12$ & 476908 & 993584 & 2332 & $208.98 \pm 42.35$ & $3.57 \pm 1.59$ & $0.28 \pm 0.12$ & $0.22 \pm 0.31$ \\
\hline SS13 & 474867 & 996734 & 2369 & $363.63 \pm 160.37$ & $4.17 \pm 2.21$ & $0.28 \pm 0.14$ & $0.11 \pm 0.10$ \\
\hline SS14 & 476457 & 994679 & 2361 & $305.08 \pm 132.08$ & $6.25 \pm 5.93$ & $0.26 \pm 0.15$ & $0.08 \pm 0.03$ \\
\hline SS15 & 477253 & 993821 & 2332 & $264.58 \pm 145.10$ & $5.58 \pm 5.09$ & $0.20 \pm 0.25$ & $0.32 \pm 0.31$ \\
\hline SS16 & 477536 & 997525 & 2402 & $375.41 \pm 84.46$ & $10.83 \pm 3.27$ & $0.37 \pm 0.24$ & $0.18 \pm 0.17$ \\
\hline SS17 & 484110 & 998745 & 2451 & $270.11 \pm 75.36$ & $2.83 \pm 1.53$ & $0.23 \pm 0.23$ & $0.07 \pm 0.02$ \\
\hline SS18 & 472301 & 993299 & 2280 & $277.84 \pm 78.85$ & $1.58 \pm 0.67$ & $0.26 \pm 0.10$ & $0.07 \pm 0.02$ \\
\hline SS19 & 486713 & 1001113 & 2448 & $206.83 \pm 34.21$ & $1.67 \pm 0.78$ & $0.01 \pm 0.03$ & $0.02 \pm 0.02$ \\
\hline SS20 & 473555 & 996064 & 2334 & $247.89 \pm 79.74$ & $7.92 \pm 6.26$ & $0.29 \pm 0.16$ & $0.14 \pm 0.83$ \\
\hline $\mathrm{SS} 21$ & 473609 & 993529 & 2306 & $185.94 \pm 22.35$ & $4.58 \pm 1.78$ & $0.30 \pm 0.13$ & $0.12 \pm 0.08$ \\
\hline
\end{tabular}




\begin{tabular}{|c|c|c|c|c|c|c|c|}
\hline $\begin{array}{l}\text { Sampling Site } \\
\text { Code/ID }\end{array}$ & UTM (X) & UTM (Y) & Elevation & $\operatorname{VOC}\left(\mu \mathrm{g} / \mathrm{m}^{3}\right)$ & CO (ppm) & $\mathrm{SO}_{2}(\mathrm{ppm})$ & $\mathrm{NO}_{2}(\mathrm{ppm})$ \\
\hline SS22 & 474039 & 990518 & 2261 & $210.58 \pm 43.30$ & $4.83 \pm 1.8$ & $0.33 \pm 0.16$ & $0.09 \pm 0.03$ \\
\hline $\mathrm{SS} 23$ & 471838 & 999838 & 2500 & $391.09 \pm 102.55$ & $3.08 \pm 2.11$ & $0.18 \pm 0.12$ & $0.09 \pm 0.03$ \\
\hline $\mathrm{SS} 24$ & 470585 & 1000002 & 2521 & $311.20 \pm 70.14$ & $3.25 \pm 2.22$ & $0.12 \pm 0.06$ & $0.07 \pm 0.02$ \\
\hline $\mathrm{SS} 25$ & 468515 & 1001055 & 2549 & $247.33 \pm 46.71$ & $2.17 \pm 1.19$ & $0.36 \pm 0.83$ & $0.07 \pm 0.01$ \\
\hline SS26 & 473193 & 996168 & 2333 & $402.76 \pm 89.33$ & $8.25 \pm 3.79$ & $0.20 \pm 0.18$ & $0.14 \pm 0.07$ \\
\hline $\mathrm{SS} 27$ & 476149 & 996476 & 2362 & $323.05 \pm 84.74$ & $6.83 \pm 2.08$ & $0.37 \pm 0.17$ & $0.13 \pm 0.86$ \\
\hline SS28 & 479187 & 995344 & 2356 & $275.42 \pm 101.64$ & $2.67 \pm 1.56$ & $0.27 \pm 0.11$ & $0.11 \pm 0.18$ \\
\hline SS29 & 472357 & 979826 & 2504 & $159.59 \pm 110.61$ & $5.17 \pm 2.33$ & $0.13 \pm 0.10$ & $0.11 \pm 0.11$ \\
\hline $\mathrm{SS} 30$ & 471014 & 1001606 & 2602 & $95.01 \pm 38.66$ & $4.08 \pm 1.78$ & $0.12 \pm 0.06$ & $0.10 \pm 0.03$ \\
\hline SS31 & 473220 & 996175 & 2346 & $95.89 \pm 27.93$ & $4.25 \pm 2.01$ & $0.10 \pm 0.04$ & $0.08 \pm 0.01$ \\
\hline SS32 & 472104 & 995943 & 2358 & $332.24 \pm 74.41$ & $6.75 \pm 2.14$ & $0.71 \pm 0.20$ & $0.44 \pm 0.37$ \\
\hline SS33 & 474779 & 983302 & 2162 & $342.49 \pm 66.14$ & $5.67 \pm 2.81$ & $0.08 \pm 0.05$ & $0.33 \pm 0.33$ \\
\hline SS34 & 474268 & 987576 & 2184 & $752.88 \pm 121.36$ & $9.75 \pm 2.60$ & $0.74 \pm 0.31$ & $0.67 \pm 0.30$ \\
\hline SS35 & 475113 & 983168 & 2152 & $330.63 \pm 73.79$ & $7.33 \pm 3.11$ & $0.60 \pm 0.23$ & $0.56 \pm 0.30$ \\
\hline SS36 & 472845 & 996203 & 2351 & $157.73 \pm 39.79$ & $8.00 \pm 4.31$ & $0.33 \pm 0.21$ & $0.10 \pm 0.08$ \\
\hline SS37 & 472772 & 997208 & 2366 & $192.26 \pm 53.26$ & $5.83 \pm 3.35$ & $0.24 \pm 0.14$ & $0.12 \pm 0.06$ \\
\hline SS38 & 471872 & 997973 & 2428 & $192.15 \pm 53.26$ & $6.42 \pm 3.60$ & $0.24 \pm 3.60$ & $0.12 \pm 0.06$ \\
\hline SS39 & 470515 & 998677 & 2469 & $308.75 \pm 90.50$ & $8.75 \pm 2.99$ & $0.25 \pm 0.09$ & $0.64 \pm 0.01$ \\
\hline SS40 & 470575 & 998672 & 2465 & $256.25 \pm 50.08$ & $8.83 \pm 3.16$ & $0.20 \pm 0.14$ & $0.07 \pm 0.01$ \\
\hline SS41 & 469959 & 998589 & 2348 & $295.08 \pm 57.87$ & $10.50 \pm 3.06$ & $0.19 \pm 0.12$ & $0.12 \pm 0.17$ \\
\hline SS42 & 468373 & 999542 & 2402 & $292.48 \pm 50.32$ & $9.83 \pm 2.37$ & $0.17 \pm 0.12$ & $0.07 \pm 0.02$ \\
\hline SS43 & 470632 & 998067 & 2452 & $200.17 \pm 50.01$ & $4.17 \pm 2.55$ & $0.18 \pm 0.13$ & $0.09 \pm 0.06$ \\
\hline SS44 & 466676 & 993044 & 2321 & $207.09 \pm 57.40$ & $4.33 \pm 2.77$ & $0.16 \pm 0.13$ & $0.09 \pm 0.06$ \\
\hline SS45 & 465051 & 992182 & 2340 & $295.94 \pm 54.73$ & $2.67 \pm 1.61$ & $0.16 \pm 0.13$ & $0.06 \pm 0.02$ \\
\hline SS46 & 472301 & 993299 & 2280 & $225.19 \pm 45.51$ & $4.25 \pm 1.66$ & $0.23 \pm 0.11$ & $0.06 \pm 0.02$ \\
\hline SS47 & 471299 & 994304 & 2320 & $231.45 \pm 82.97$ & $3.58 \pm 1.83$ & $0.23 \pm 0.18$ & $0.07 \pm 0.02$ \\
\hline SS48 & 470372 & 994596 & 2324 & $250.83 \pm 49.80$ & $2.42 \pm 1.56$ & $0.17 \pm 0.12$ & $0.11 \pm 0.15$ \\
\hline SS49 & 469564 & 993626 & 2315 & $252.53 \pm 77.92$ & $3.40 \pm 2.64$ & $0.19 \pm 0.14$ & $0.06 \pm 0.01$ \\
\hline SS50 & 470616 & 990975 & 2224 & $227.36 \pm 83.37$ & $3.08 \pm 1.62$ & $0.23 \pm 0.10$ & $0.06 \pm 0.01$ \\
\hline SS51 & 468230 & 990470 & 2241 & $216.45 \pm 84.97$ & $3.92 \pm 2.19$ & $0.12 \pm 0.11$ & $0.07 \pm 0.02$ \\
\hline SS52 & 480163 & 997515 & 2395 & $216.08 \pm 81.03$ & $3.92 \pm 2.19$ & $0.12 \pm 0.11$ & $0.07 \pm 0.02$ \\
\hline SS53 & 480281 & 997633 & 2404 & $303.42 \pm 49.77$ & $2.42 \pm 1.00$ & $0.16 \pm 0.11$ & $0.06 \pm 0.01$ \\
\hline SS54 & 469389 & 996070 & 2355 & $218.79 \pm 69.75$ & $3.75 \pm 2.05$ & $0.18 \pm 0.11$ & $0.09 \pm 0.03$ \\
\hline SS55 & 471047 & 996121 & 2363 & $220.50 \pm 87.87$ & $3.67 \pm 2.10$ & $0.20 \pm 0.14$ & $0.09 \pm 0.02$ \\
\hline SS56 & 470680 & 997173 & 2400 & $200.17 \pm 50.01$ & $3.58 \pm 1.93$ & $0.20 \pm 0.14$ & $0.09 \pm 0.06$ \\
\hline SS57 & 471145 & 998288 & 2454 & $334.05 \pm 75.67$ & $7.75 \pm 3.14$ & $0.18 \pm 0.17$ & $0.08 \pm 0.02$ \\
\hline SS58 & 470855 & 998598 & 2464 & $303.42 \pm 49.71$ & $4.83 \pm 2.72$ & $0.17 \pm 0.12$ & $0.09 \pm 0.02$ \\
\hline SS59 & 471352 & 998587 & 2453 & $406.75 \pm 74.82$ & $4.75 \pm 2.63$ & $0.26 \pm 0.14$ & $0.08 \pm 0.03$ \\
\hline SS60 & 471369 & 998572 & 2410 & $388.50 \pm 185.04$ & $3.50 \pm 2.32$ & $0.21 \pm 0.16$ & $0.06 \pm 0.01$ \\
\hline SS61 & 463174 & 1002325 & 2611 & $196.67 \pm 59.54$ & $4.17 \pm 2.37$ & $0.18 \pm 0.10$ & $0.07 \pm 0.02$ \\
\hline SS62 & 464939 & 10002640 & 2603 & $182.58 \pm 44.06$ & $2.75 \pm 1.82$ & $0.18 \pm 0.09$ & $0.07 \pm 0.01$ \\
\hline SS63 & 466389 & 1002171 & 2563 & $195.00 \pm 59.07$ & $3.25 \pm 1.76$ & $0.18 \pm 0.09$ & $0.07 \pm 0.02$ \\
\hline SS64 & 480280 & 994818 & 2335 & $212.50 \pm 72.51$ & $2.92 \pm 1.68$ & $0.18 \pm 0.11$ & $0.07 \pm 0.01$ \\
\hline SS65 & 481250 & 993917 & 2320 & $249.65 \pm 93.50$ & $3.92 \pm 2.02$ & $0.16 \pm 0.12$ & $0.06 \pm 0.01$ \\
\hline
\end{tabular}

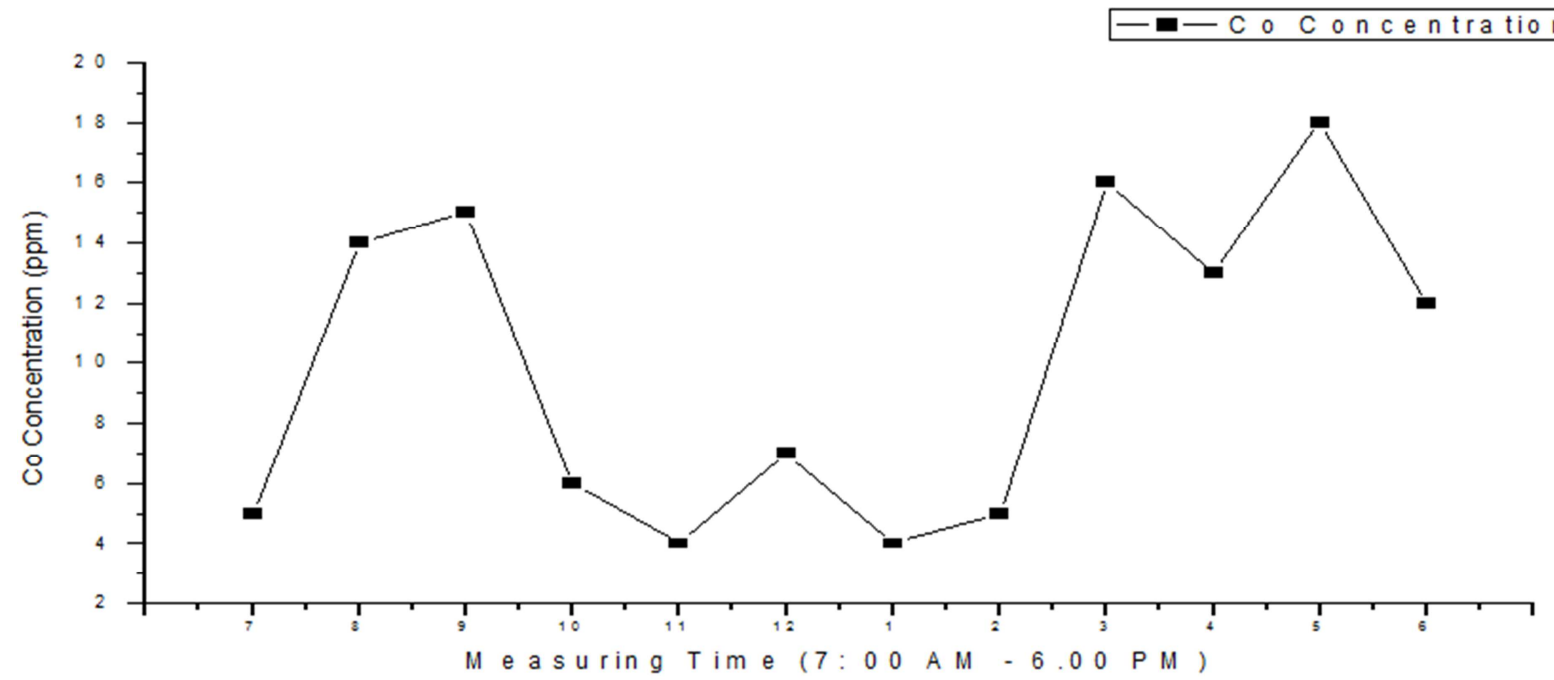

Figure 4. Typical day CO concentration trends at SS3 (Megenagna train ticket sell). 
The result of this study shows there was temporal variation of $\mathrm{CO}$ concentration at all sites under study and the variation was significant $(p<0.05)$. Figure 4 below shows the patterns of $\mathrm{CO}$ concentration on particular measuring day at Megenagna; thickly crowded road part in Addis Ababa (SS3). There was high $\mathrm{CO}$ concentration during the rush hours in the morning (8:00 am- 9:00 am) and early afternoon (04:00-06:00 pm) and lower at 10:00 am -03:00 pm [18, 19, Figure 4). The daily (hourly) maximum CO concentration recorded during the study period was $18 \mathrm{ppm}$ for SS14 and SS3 sampling sites on rushing hours of the day on 9:00 am and 5:00 pm respectively [Figure 4]. The high CO concentration in the early morning and late afternoon was due to the congested vehicular staging and stagnation of temperature in the city $[3,16]$. The low concentration of $\mathrm{CO}$ at mid-day was because of the photochemical reaction taking place by sunlight in the presence of hydrocarbons as $\mathrm{CO}$ is converted to carbon dioxide [3].

\subsection{VOC Concentration}

The overall VOC concentration mean \pm SD during the sampling period was $317.52 \pm 221.52 \mu \mathrm{g} / \mathrm{m}^{3}$. The arithmetic mean and standard deviation concentrations of VOC at all the sampling site of roadside presented in the Table 2, SS1, SS2, SS3, SS4, SS5, SS6, SS26, SS34 and SS59 are sites with VOC concentration of above the overall mean \pm SD [Table 2]. Scholar [20] also reported lower total VOC concentrations of $129 \mu \mathrm{g} / \mathrm{m}^{3}$ on roadsides of Philippines. The VOC concentration found in this study was higher than the value reported for Ghent city $\left(54 \mu \mathrm{g} / \mathrm{m}^{3}\right)$, similar with that of Addis Ababa $\left(318 \mu \mathrm{g} / \mathrm{m}^{3}\right)$ and lower than that reported for Hanoi city $\left(507 \mu \mathrm{g} / \mathrm{m}^{3}\right)[15]$.

The finding of the present study is indicating that, there is a spatial variation of VOC concentration over the selected study sites. The highest and lowest VOC concentration during the sampling period was $752.88 \pm 121.36 \mu \mathrm{g} / \mathrm{m}^{3}$ and $157.73 \pm 39.79 \mu \mathrm{g} / \mathrm{m}^{3}$ at SS34 and SS36 sampling sites respectively. More than ten (10) sites under study have VOC concentration above mean $\pm \mathrm{SD}$ and most of the sampling sites have VOC Concentration below mean \pm SD [Table 2]. The study by [22] also reported the spatial variation of VOC in urban areas of Dhaka city of Bangladesh.

Temporal variation of VOC concentration during the study period at the entire study site was not significant as such even though the overall concentration trend of VOC concentration at all sites was similar. The pattern of particular measuring day, Megenagna site (SS3) shown in Figure 2. There was high VOC concentration at most sampling sites during the rush hours in the morning (8:00- 9:00 am) and early afternoon (04:00 pm) and lower 10:00 -03:00 pm [Figure 2, 5]. Temporal variation of VOC; low in mid night and high at early in the morning continuously increasing up to 10:00 am was reported in [23].

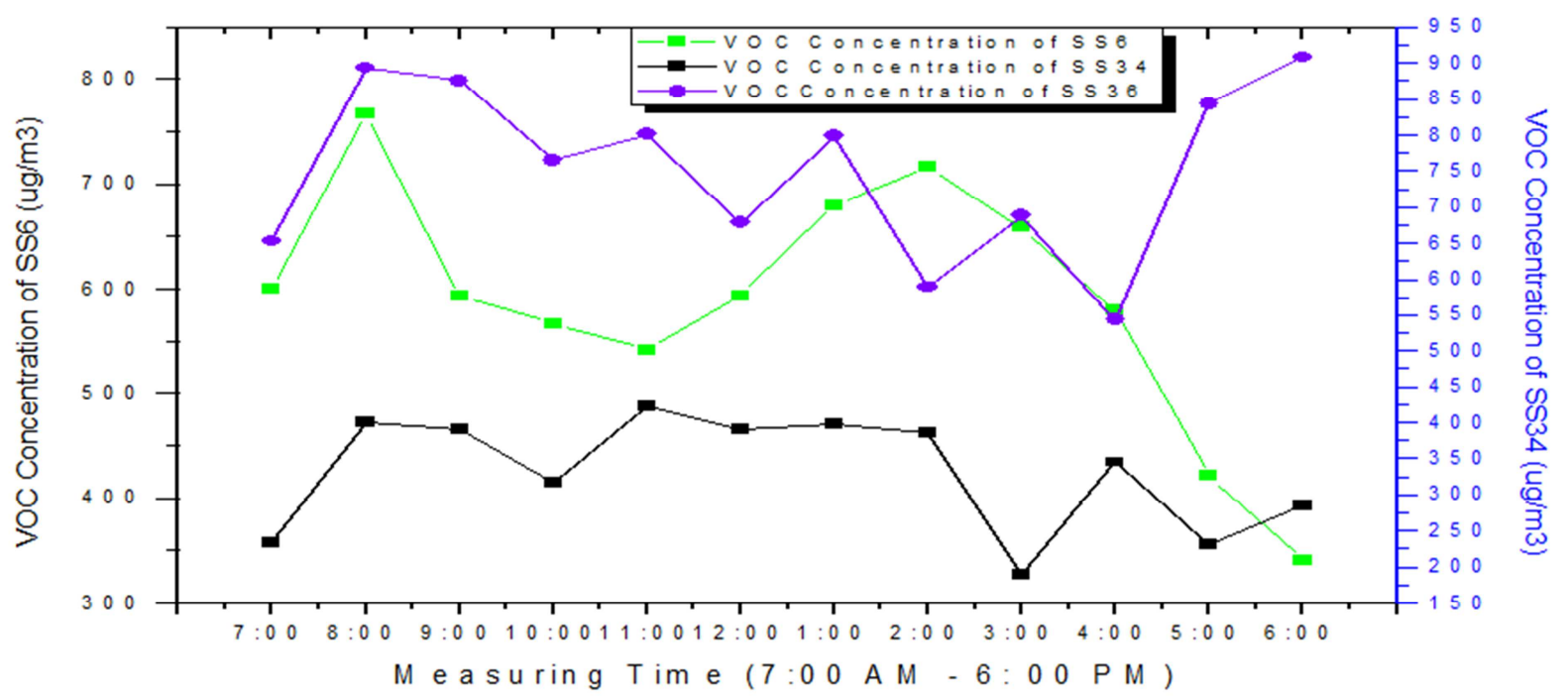

Figure 5. The daily VOC concentration patterns on particular day of sites SS6, SS34 \& SS36 sites.

\section{3. $\mathrm{NO}_{2}$ Concentration}

The overall mean $\pm \mathrm{SD} \mathrm{NO}_{2}$ concentration during the sampling period was $0.12 \pm 0.16 \mathrm{ppm}$ [Table 2]. The highest and lowest $\mathrm{NO}_{2}$ concentrations were recorded at site SS34 $(0.67 \pm .30 \mathrm{ppm})$ and SS6 $(0.05 \pm 0.02 \mathrm{ppm})$. The study conducted in two Ugandan cities also reported $0.025 \mathrm{ppm}$ $\mathrm{NO}_{2}$ concentration [1]. Furthermore, the study by [17] conducted in Addis Ababa city, reported that the $\mathrm{NO}_{2}$ concentration at the sites under their study was not detectable.

The arithmetic mean and standard deviation (mean \pm SD) concentrations of $\mathrm{NO}_{2}$ at all the sampling site of roadside presented in the Table1. The result of this study shows that there is a spatial variation of $\mathrm{NO}_{2}$ concentration. The overall $\mathrm{NO}_{2}$ concentration trend at all sampling sites were similar [Figure 6]. Sites such as; SS2, SS26, SS34, SS35 and SS39 have high concentration of $\mathrm{NO}_{2}$ then mean $\pm \mathrm{SD}$ and are located in the high congestion of traffic zones in Addis 
Ababa [Table 2]. The highest and lowest $\mathrm{NO}_{2}$ concentrations were recorded at sites SS39 and SS6 respectively [Table 2]. Figure 6 below shows the trends of $\mathrm{NO}_{2}$ concentration of SS6 and SS39 during particular day during the study period, which shows directly proportional to traffic and congesting of traffic.

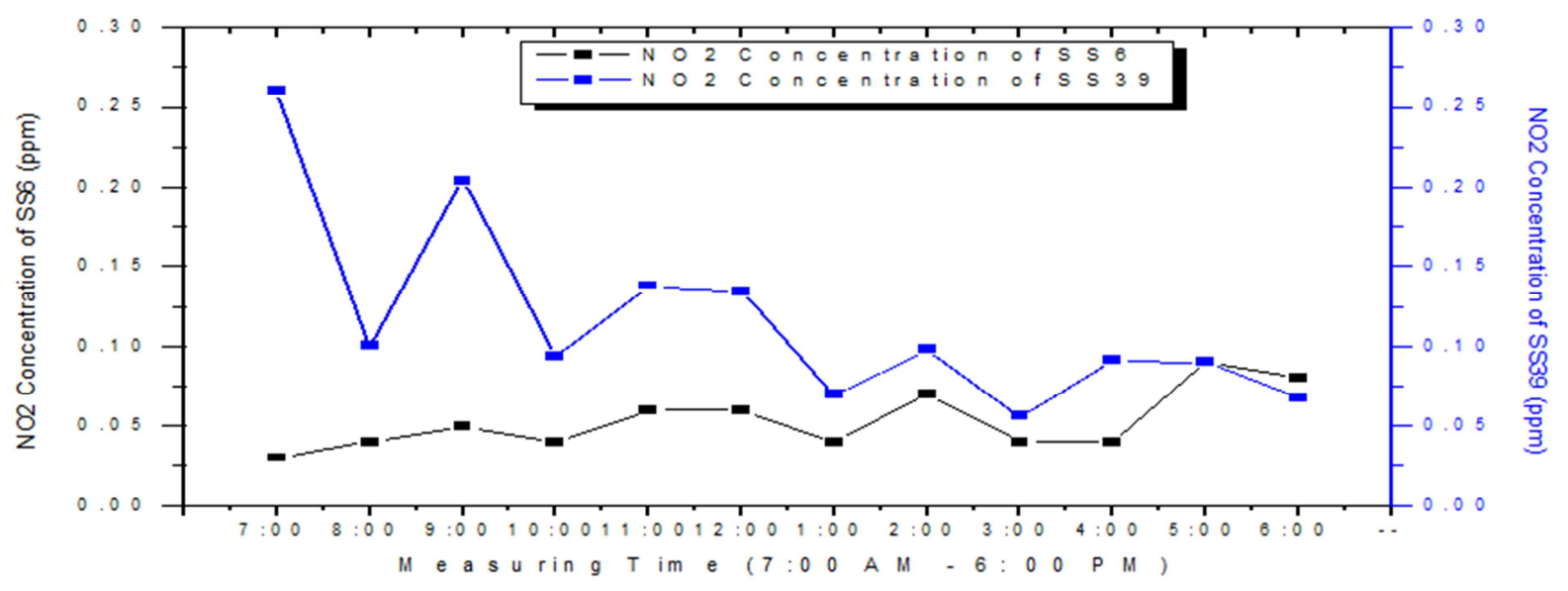

Figure 6. The daily $\mathrm{NO}_{2}$ concentration Trends in particular day of sites SS6 (Summit Condominium last gate) \& SS39 (Merkato big bus Station).

Temporal variation of $\mathrm{NO}_{2}$ concentration at all sites under study was observed. The trend of $\mathrm{NO}_{2}$ concentration at all sites was similar [Figure 6]. There was high $\mathrm{NO}_{2}$ concentration during the rush hours in the morning (8:00 9:00 am) and early afternoon (04:00-06:00 pm) and lower 10:00 am -03:00 pm [Figure 6].

\section{4. $\mathrm{SO}_{2}$ Concentration}

The arithmetic mean and standard deviation (mean \pm SD)

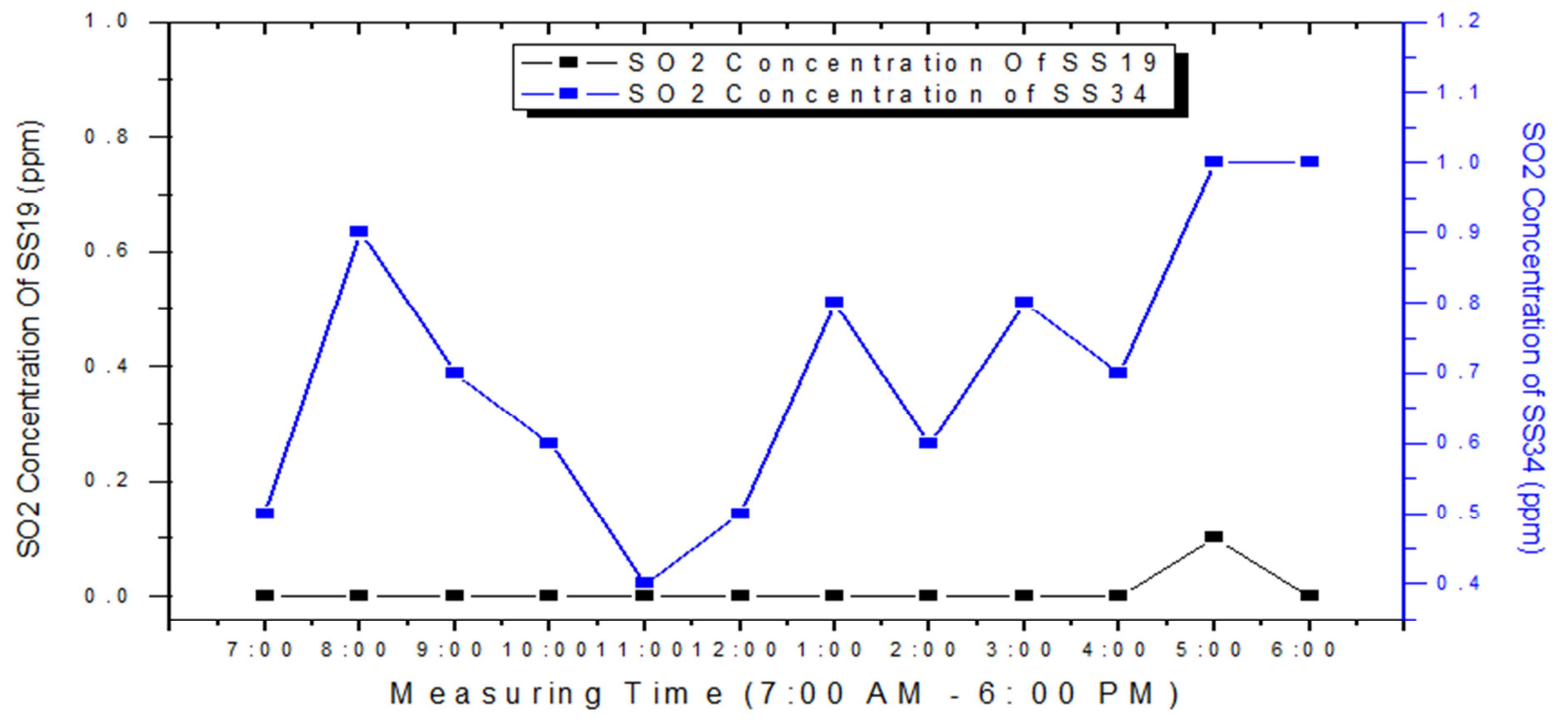

Figure 7. Trends of $\mathrm{SO}_{2}$ at sites with highest and lowest concentration.
The highest and lowest $\mathrm{SO}_{2}$ concentrations were recorded at site $\operatorname{SS} 33(0.74 \pm 0.31 \mathrm{ppm})$ and $\operatorname{SS} 19(0.01 \pm 0.03 \mathrm{ppm})$ respectively [Table 2]. The roadside $\mathrm{SO}_{2}$ concentration of the site with highest and lowest is indicated in figure 7 . The results shows that no remarkable spatial and temporal variation of $\mathrm{SO}_{2}$ concentration (not significant at $\mathrm{p}<0.05$ ), but the overall concentration trends of $\mathrm{SO}_{2}$ concentration at all sites were similar [Figure7]. concentrations of $\mathrm{SO}_{2}$ at all the sampling site of roadside presented in the Table 1. The overall arithmetic mean and standard deviation (mean $\pm \mathrm{SD}$ ) concentration of $\mathrm{SO}_{2}$ during the study period was $0.23 \pm 0.20 \mathrm{ppm}$ perhaps the climatic condition of Addis Ababa may facilitate the adsorption of the gaseous pollutants such as $\mathrm{SO}_{2}$ on particulate matter [1]. As reported by [17] the $\mathrm{SO}_{2}$ concentration at the sites under their study in Addis Ababa city was not detectable.

\section{Conclusion}

The current study was carried out to assess the concentration of four ambient air pollutants in Addis Ababa City focusing on the road side to understand their distribution and provide the overview of the pollutants concentration. The roadsides concentration (mean $\pm \mathrm{SD}$ ) of $\mathrm{CO}, \mathrm{VOC}, \mathrm{NO}_{2}$ and $\mathrm{SO}_{2}$ found were $4.52 \pm 3.60,317.52 \pm 221.52,0.12 \pm 0.16$ 
and $0.23 \pm 0.20$ respectively. The result of this study for all air pollutants under study were higher than the previous studies result reported by different researchers. Therefore, air pollution in the city needs to be monitored continuously and exploring mitigation mechanisms should be put in place by concerning government bodies or non-government organization.

\section{Acknowledgements}

The authors wish to thank Center for Environmental Science, College of Natural and Computational Science of Addis Ababa University for providing instrument used for conducting this study; financial support and back-up to undertake this study.

\section{References}

[1] Kirenga BJ, Meng Q, Gemert F Van, Aanyu-tukamuhebwa H. The State of Ambient Air Quality in Two Ugandan Cities : A Pilot Cross-Sectional Spatial Assessment, (2015), 8075-91.

[2] Kumar P, Morawska L, Martani C, Biskos G, Neophytou M, Di Sabatino S. The rise of low-cost sensing for managing air pollution in cities. Environ Int., (2015), 75:199-205.

[3] Kume A, Charles K, Berehane Y, Anders E, Ali A. Magnitude and variation of traffic air pollution as measured by $\mathrm{CO}$ in the City of Addis Ababa, Ethiopia. Ethiop J Heal Dev., (2010), 24 (3):156-66.

[4] Molina MJ, Molina LT. Megacities and atmospheric pollution. J Air Waste Manag Assoc., (2004), 54 (6):644-80.

[5] United Nations, Department of Economic and Social Affairs. World Urbanization Prospects: The 2009 Revision. New York: United Nations, (2010).

[6] United Nations Energy Program. Integrated assessment of black carbon and tropospheric ozone. Nairobi: United Nations Energy Program and World Meteorological Organization, (2011). Available: http://www.unep.org/dewa/Portals/67/pdf/BlackCarbon_report .pdf.

[7] AsifFaiz, Christopher S. Weaver, Michael P. Walsh. Air pollution from motor vehicles: Standards and technologies for controlling emission, (1996).

[8] Rao, S., Chirkov, V., Dentener, F., van Dingenen, R., Pachauri, S., Purohit, P., Amann, M., Heyes, C., Kinney, P., Kolp, P., Klimont, Z., Riahi, K. and Schoepp, W. Estimation of the Global Health Impacts of Air Pollution. IIASA Interim Report. IIASA, Laxenburg, Austria, IR-11-035, (2011).http://pure.iiasa.ac.at/9802/
[9] Kinney PL, Gichuru MG, Volavka-Close N, Ngo N, Ndiba PK, Law A. Traffic impacts on PM2.5 air quality in Nairobi, Kenya. Environ Sci Policy, (2011).

[10] Marsden G, Bell M. Road Traffic Pollution Monitoring and Modeling Tools and the UK National Air Quality Strategy. Local Environ, (2001), 6 (2):181-97. Available from: http://eprints.whiterose.ac.uk/2554/.

[11] Fenger, J. Urban air quality. Atmospheric Environment, (1999), 33, 4877-4900.

[12] Environmental Protection Agency. National ambient air quality standards (NAAQS), (2014). (Available at http://www3.epa.gov/ttn/naaqs/criteria.html).

[13] WHO Ambient (Outdoor) Air Quality Database. Geneva: World Health Organization, (2014). http://www.who.int/phe/health_topics/outdoorair/databases/cit ies-2014/en/.

[14] WHO. Our Planet, Our Health, Our Future. Public Heal Environ Dep, (2012), 64. Available from: www.who.int/globalchange/.../reports/health_rioconventions.p df.

[15] Roychowdhury A, Chandola P, Chattopadhyaya V. Urban Air Quality Management in Ethiopia: A Guidance Framework, (2016); Available from:

http://www.cseindia.org/userfiles/ethiopia-report.pdf

[16] Jovanelly TJ, Okot-okumu J, Nyenje R, Namaganda E. Comparative Assessment of Ambient Air Standards in Rural Areas to Uganda City Centers, (2017), 3 (1): 371-80.

[17] Alemu D. Impact of vehicle emissions on air pollution in Addis Ababa, (2012), 26.

[18] Etyemezian V, Tesfaye M, Yimer A, Chow JC, Mesfin D, Nega T, et al. Results from a pilot-scale air quality study in Addis Ababa, Ethiopia. Atmos Environ, (2005).

[19] Mahalakshmi D V., Sujatha P, Naidu CV, Chowdary VM. Contribution of vehicular emission on urban air quality: Results from public strike in Hyderabad. Indian J Radio Sp Phys., (2014), 43 (6): 340-8.

[20] Parao AE. Volatile Organic Compounds in Urban and Industrial Areas in the Philippines. Faculty of Bioscience Engineering Center for Environmental Science and Technology, (2012).

[21] MitaliParvin Promoter. MitaliParvin. Indoor-Outdoor Volatile Org Compound levels Urban Ind Area Dhaka City, Bangladesh, (2014).

[22] Tiwari V, Hanai Y, Masunaga S. Ambient levels of volatile organic compounds in the vicinity of petrochemical industrial area of Yokohama, Japan. Air Qual. Atmos Heal., (2010), 3 (2): 65-75. 